\title{
Effectiveness and safety of intravenous ferric carboxy maltose in anaemic women attending gynecological unit
}

\author{
Bharathi K. R., Pooja Bhat* \\ Department of Obstetrics and Gynecology, Adichunchungiri Institute of Medical Sciences, B G Nagara, Karnataka, India
}

Received: 31 December 2021

Accepted: 17 January 2022

\author{
*Correspondence: \\ Dr. Pooja Bhat, \\ E-mail: poojabhatmed@gmail.com
}

Copyright: $\odot$ the author(s), publisher and licensee Medip Academy. This is an open-access article distributed under the terms of the Creative Commons Attribution Non-Commercial License, which permits unrestricted non-commercial use, distribution, and reproduction in any medium, provided the original work is properly cited.

\begin{abstract}
Background: Anaemia is a significant problem worldwide, particularly in women. Several intravenous iron preparations are available for the treatment of anaemia. Some of them cause life-threatening anaphylactic reactions while others require multiple small infusions to prevent iron reactions. Ferric carboxy maltose (FCM), a non-dextran intravenous iron, is safe and effective option that can be administered as single high dose without serious adverse effects. Methods: A prospective study was undertaken in the department of obstetrics and gynecology, Adichunchungiri institute of medical sciences, B G Nagara, from August 2020 to November 2021 in which 50 cases with iron deficiency anaemia were enrolled. IV FCM $1 \mathrm{~g}$ was given. Change in the laboratory parameters such as haemoglobin $(\mathrm{Hb})$, mean corpuscular value, serum ferritin levels over a 4 weeks period were observed.

Results: A significant increase in mean $\mathrm{Hb}$ from 8.14 to $11.71 \mathrm{~g}$ was observed in patients treated with FCM after 4 weeks of therapy. Majority belonged to age group of 21-30 years and moderate type of anaemia was most common. No serious drug reaction was reported.

Conclusions: IV FCM is safe and effective option for improving $\mathrm{Hb}$ in iron deficiency anaemia, in terms of restoring iron stores in short duration of time as well as patient compliance.
\end{abstract}

Keywords: FCM, Iron deficiency anaemia, Parenteral therapy, Iron infusion

\section{INTRODUCTION}

Iron deficiency anaemia is a significant problem globally, particularly in women. The WHO defines anaemia as $\mathrm{Hb}$ value below $12 \mathrm{~g} / \mathrm{dl}$ in non-pregnant women over 15 years of age and below $1 \mathrm{~g} / \mathrm{dl}$ in pregnant women. ${ }^{1}$ Half of the world's anaemic burden is contributed by iron deficiency anaemia alone. ${ }^{2}$ In 2019, global anaemia prevalence was $29.9 \%$ in women of reproductive age, equivalent to over half a billion women aged 15-49 years. The condition has an alarming prevalence rate among pregnant women, that is, $36.5 \%$ followed by $29.6 \%$ in non-pregnant women. ${ }^{3}$ According to the National family health survey 4(NFHS4), 53\% of all women aged 15-49 years were anaemic in India. ${ }^{4}$ Iron stores are depleted whenever there is an imbalance between iron uptake and utilization, thus causing iron deficiency anemia. ${ }^{5}$ Erythropoiesis is suppressed due to iron deficiency, thereby reducing $\mathrm{Hb}^{6}$

Anaemia affects productive as well as reproductive abilities of women in terms of poor work capacity, decreased energy, diminished quality of life, fatigue or lead to infertility. ${ }^{7}$ During pregnancy, it can result in intrauterine growth restriction, preterm labour, low birth weight and increased maternal and perinatal mortality. Poor nutrition, low socio-economic status and associated diseases contribute to iron deficiency anemia. ${ }^{89}$

Laboratory parameters for diagnosis of iron deficiency anaemia include complete blood count, serum iron, serum ferritin, transferrin saturation and total iron binding capacity. Definitive diagnosis is bone marrow examination 
that is seldom done routinely as it is painful and invasive procedure.

Iron deficiency anaemia can be managed by appropriate iron replacement. Oral therapy is the first line of treatment. Parenteral therapy is resorted to in cases of noncompliance, malabsorption and when rapid correction of anaemia is necessary. ${ }^{10}$ Iron sorbitol and iron dextran are age old parenteral preparations that are abandoned due to unpredictable anaphylaxis and dosage frequency.

FCM is a stable ferric complex bound tightly with ferric hydroxide core stabilized by a carbohydrate polymer. It is a novel dextran free agent approved by food and drug administration for rapid and high dose replenishment in cases of iron deficiency anaemia. ${ }^{11}$ It has minimal side effects such as nausea, vomiting, headache, injection site reactions, flushing dizziness.

\section{Objectives}

The objectives were to study the effectiveness and safety of FCM in achieving desired levels of laboratory biomarkers such as $\mathrm{Hb}$, mean corpuscular value, serum ferritin as prescribed by WHO guidelines; to identify and prevent any possible adverse drug reaction in patients on FCM.

\section{METHODS}

The study was conducted at department of OBG, Adichunchungiri institute of medical sciences, B G Nagara, Karnataka, India, from August 2020 to November 2021

Fifty women diagnosed with iron deficiency anaemia admitted or present for consultation in the OBG ward were enrolled in the study period. Ethical clearance was obtained from the institutional ethics committee. Written informed consent was obtained from the study participants.

\section{Inclusion criteria}

All non-pregnant women attending OBG unit with iron deficiency anaemia, who exhibited non-compliance to oral iron and provided consent were included.

\section{Exclusion criteria}

Patients with severe anemia- $\mathrm{Hb}<7$; cases lost for follow up after 4 weeks; patients with uncontrolled hypertension/impaired renal disease/impaired liver function/heart disease were excluded.

Relevant clinical history and patient details were entered in a structured data collection form. Initial assessment of anaemia, as per WHO guidelines were tabulated into mild, moderate/severe considering laboratory parameters- peripheral blood smear, complete hemogram and serum ferritin.

Required iron dose were calculated on the basis of Ganzoni's formula,

Iron requirement $(\mathrm{mg})=$ body weight $(\mathrm{kg}) \times$ targetHb $(g \%)$ - actual $\mathrm{Hb}(\mathrm{g} \%) \times 2.4+$

$500 \mathrm{mg}$ (to replenish iron stores).

Study participants were given $1000 \mathrm{mg}$ of IV FCM diluted in $250 \mathrm{ml}$ of normal saline over 15 minutes as a single dose. Test dose was given prior to full dose to check for any adverse reaction. Study participants were observed for one hour for side effects such as nausea, vomiting, headache, flushing, injection site reactions, dizziness. In case of any adverse drug reaction, the infusion was stopped, documented and the patient was treated for the respective adverse drug event.

After the treatment, the patient's progress towards accomplishment of goal of therapy and outcomes were analysed at the end of 4 weeks. To calculate the mean SD, descriptive analysis of all the explanatory and outcome parameters using frequency and proportions for categorical variables were as in mean and SD for continuous variables.

Student paired t test was used to compare the mean $\mathrm{Hb}$ ( $\mathrm{g} \%$ ) before and after FCM injection. Wilcoxon signed rank test was used to compare the mean serum ferritin levels pre and post infusion among study patients, the level of significance was significant if $\mathrm{p}$ value was less than 0.05. Statistical analysis was performed using SPSS (statistical package for social sciences) for windows version 22.0 released 2013. Armonk, NY:IBM corp.

\section{RESULTS}

A total of 50 cases with iron deficiency anaemia were studied over a period of 1 year. The demographic profile and the baseline parameters which include age, parity, baseline $\mathrm{Hb}$ and serum ferritin levels were documented. All the study participants had iron deficiency anaemia which was confirmed by peripheral blood smear and blood indices.

As described in Table 1, the most common age group to present with anaemia was $21-30$ years, that is, $64 \%$ of all the cases, followed by 31-40 years age group (18\%) (Table $1)$.

In the study participants, the most common type of anaemia was microcytic hypochromic anaemia with moderate type, seen in $88 \%$ cases, followed by severe type seen in $8 \%$ of cases (Table 2).

Data showing mean increase in $\mathrm{Hb}$ and serum ferritin post transfusion (Table 3). 
Table 1: Age distribution among study patients.

\begin{tabular}{|llll|}
\hline Variables & Category & $\mathbf{N}$ & $\%$ \\
\hline \multirow{3}{*}{ Age (in years) } & $15-20$ & 7 & 14 \\
& $21-30$ & 32 & 64 \\
\cline { 2 - 4 } & $31-40$. & 9 & 18 \\
\hline & $>40$ & 2 & 4 \\
\hline
\end{tabular}

Table 2: Distribution of study patients based on peripheral smear finding and severity of anaemia.

\begin{tabular}{|c|c|c|c|}
\hline Variables & Category & $\mathbf{N}$ & $\%$ \\
\hline \multicolumn{4}{|c|}{ Distribution of study patients based on peripheral smear finding } \\
\hline Peripheral smear & Microcytic hypochromic & 50 & 100 \\
\hline \multicolumn{4}{|c|}{ Distribution of study patients based on severity of anaemia } \\
\hline \multirow{3}{*}{ Anaemia } & Mild & 2 & 4 \\
\hline & Moderate & 44 & 88 \\
\hline & Severe & 4 & 8 \\
\hline
\end{tabular}

Table 3: Comparison of mean Hb before and after FCM injection and comparison of mean serum ferritin levels pre and post transfusion among study patients.

\begin{tabular}{|c|c|c|c|c|c|c|}
\hline Parameters & Time & $\mathbf{N}$ & Mean & SD & Mean Diff & P value \\
\hline \multicolumn{7}{|c|}{ Comparison of mean $\mathrm{Hb}(\mathrm{gm} \%)$ before and after FCM injection among study patients using student paired t test } \\
\hline \multirow{2}{*}{$\mathrm{Hb}$} & Before FCM Inj. & 50 & 8.14 & 0.99 & \multirow{2}{*}{-3.57} & \multirow{2}{*}{$<0.001^{*}$} \\
\hline & After FCM Inj. & 50 & 11.71 & 0.74 & & \\
\hline \multicolumn{7}{|c|}{$\begin{array}{l}\text { Comparison of mean serum ferritin levels pre and post transfusion among study patients using Wilcoxon signed } \\
\text { rank test }\end{array}$} \\
\hline \multirow{2}{*}{ S. ferritin } & Pre transfusion & 50 & 32.11 & 12.81 & \multirow{2}{*}{-83.43} & \multirow{2}{*}{$<0.001^{*}$} \\
\hline & Post transfusion & 50 & 115.54 & 26.30 & & \\
\hline
\end{tabular}

Table 4: Distribution of adverse reaction of FCM injection among study patients.

\begin{tabular}{|lll|l|}
\hline Variables & Category & $\mathbf{N}$ & $\%$ \\
\hline & Nausea & 3 & 6 \\
\cline { 2 - 4 } & Vomiting & 2 & 4 \\
\cline { 2 - 4 } Adverse reaction of FCM injection & Headache & 1 & 2 \\
\cline { 2 - 4 } & Inj. Site reactions & 1 & 2 \\
\cline { 2 - 4 } & Flushing & 1 & 2 \\
\hline & Dizziness & 1 & 2 \\
\cline { 2 - 4 } & Nil & 41 & 82 \\
\hline
\end{tabular}

The mean $\mathrm{Hb}$ after treatment with FCM was $11.7 \mathrm{gm} \%$, found to be statistically significant with p value of $<0.001$. The mean increase in $\mathrm{Hb}$ level is $3.5 \%$ in FCM, serum ferritin 83.43 after 4 weeks of therapy. The rise in $\mathrm{Hb}$ levels and serum ferritin concentration were found to be statistically significant ( $\mathrm{p}$ value $<0.001$ ).

Data showing adverse drug reactions occurred at the time of infusion (Table 4). No major adverse drug events were noted during the study period.

\section{DISCUSSION}

In the present study, we studied the efficacy and safety of FCM in iron deficiency anaemia, not only for correction of deficit in the $\mathrm{Hb}$ level but also for restitution of iron stores, this treatment modality had a significant post transfusion rise in $\mathrm{Hb}$ levels and ferritin levels which was similar to previous studies. The most common age group was 21-30 years and moderate anaemia was most prevalent.

The macromolecular design of ferric hydroxide carbohydrate complex allowed controlled delivery of iron to cells in reticulo-endothelial system and subsequent delivery to iron binding protein, ferritin and transferrin with sustained, release of ionic iron in to the serum.

Advantages of FCM being, since it was a non-dextran, it was more stable complex and had low immunogenic potential with less predisposition to anaphylactic reactions. 
Hence all these properties permitted the administration of large dosing, $15 \mathrm{mg} / \mathrm{kg}$ maximum $1000 \mathrm{mg} /$ infusion in a single and rapid session $/ 15$ minutes infusion. The average increase of haemoglobin after 4 weeks was $3.5 \%$, serum ferritin was $83.43 \mathrm{ng} / \mathrm{dl}$. Patient compliance was good. The rise in $\mathrm{Hb}$ levels and serum ferritin concentration were found to be statistically significant $\mathrm{p}<0.001$.

Onken et al evaluated 507 patients with iron deficiency anaemia. ${ }^{12}$ The A group received 2 doses of $750 \mathrm{mg}$ injection FCM one week apart. B group received oral iron. $\mathrm{C}$ group included patients who did not respond to oral iron and were given injectable iron. Group D patients received IV iron from start of their care. The conclusion from the study proved that injection FCM was safer and more efficacious in improving the haemoglobin status in patients with iron deficiency anaemia.

Mahey et al conducted a study on comparison of intravenous FCM and iron sucrose injections in patients presenting with abnormal uterine bleeding. ${ }^{13}$ A total of 60 patients were observed. Initially, injection FCM showed rapid improvement in haemoglobin levels as compared to iron sucrose. But, the rise in haemoglobin in both the groups was comparable at the end of 12 weeks.

Evstatiev et al also compared injection FCM with iron sucrose in patients with inflammatory bowel disease with iron deficiency anaemia. ${ }^{14} 485$ patients were included in the study. Though both showed comparable rise in haemoglobin levels after a 12 week period, injection FCM had a better compliance as well as efficacy.

Wyck et al conducted a randomised controlled trial to compare the efficacy of injection FCM with oral iron in patients with heavy uterine bleeding. ${ }^{15} 477$ women with anaemia were studied and it was concluded that injection FCM was better than oral iron in faster rise of $\mathrm{Hb}$ and in improving the quality of life of the patients.

\section{Strengths}

Since FCM was a recently approved drug for the purpose of correction of iron deficiency anaemia, limited data was available with regards to its safety and efficacy. This study was carried out to provide an insight regarding adverse effects as it was a prospective study. One hour monitoring of all patients was done after the infusion to ensure keen observation and maximum safety.

\section{Limitations}

Small sample size, short duration of time and carried out on non-pregnant women were the major limitations of the study. More laboratory parameters needed to be considered. Comparison had to be done with other parenteral iron preparations available in the market.

\section{CONCLUSION}

Iron deficiency anaemia is a global problem that is undermined, prompt correction will significantly reduce morbidity and mortality. This study highlights that single dose $1 \mathrm{~g}$ FCM infusion is safe and effective parenteral therapy for iron deficiency anaemia especially in those who require rapid replenishment in short period of time and with poor compliance to oral iron.

\section{Funding: No funding sources}

Conflict of interest: None declared

Ethical approval: The study was approved by the Institutional Ethics Committee

\section{REFERENCES}

1. WHO. Fact sheet: Nutritional anemias. Report of a WHO scientific group. Geneva, World Health Organization, 1968. Available at: http://apps.who.int/iris/bitstream/10665/40707/1/WH O_TRS_405.pdf. Accessed on 20 December 2021.

2. WHO. Fact sheet: Iron deficiency anemia assessment, prevention, and control: a guide for programme managers,2001. Available at: https://apps.who.int/nutrition/publications/micronutri ents/anaemia_iron_deficiency/WHO_NHD_01.3/en/i ndex.html. Accessed on 20 December 2021.

3. WHO. Fact sheet: Anemia in women \& children, 2021. Available at: https://www.who.int/healthtopics/anaemia\#tab=tab_1. Accessed on 20 December 2021.

4. Government of India. National Family Health Survey 4- key indicators: 2015-2016. National Fam Health Surv. 2016;4:1-8.

5. Abbaspour N, Hurrell R, Kelishadi R. Review on iron and its importance for human health. J Res Med Sci. 2014;19(2):164-74.

6. Gasche C, Lomer MCE, Cavill I, Weiss G. Iron, anemia, and inflammatory bowel diseases. Gut. 2004;53(8):190-7.

7. CDC. Recommendations to prevent and control iron deficiency in the United States. Centers for Disease Control and Prevention. MMWR Recomm Rep. 1998;47(3):1-29.

8. Bentley ME, Griffiths PL. The burden of anemia among women in India. Eur $\mathbf{J}$ Clin Nutr. 2003;57(1):5260.

9. Kielmann K. Thresholds of morbidity among women in a peri-urban community of Maharashtra, India: conceptual and methodological issues. J Health Psychol. 2003;8(5):525-38.

10. Anouk P, Ganzevoort W. Safety and efficacy of ferric carboxymaltose in anemic pregnant women: A retrospective case control study. Obstet Gynecol Int. 2015;2015:728952.

11. Kulnigg S, Stoinov S, Simanenkov V, Dudar LV, Karnafel W, Garcia LC, et al. A novel intravenous iron formulation for treatment of anemia in inflammatory bowel disease: the ferric 
carboxymaltose (FERINJECT) randomized controlled trial. Am J Gastroenterol. 2008;103(5):1182-92.

12. Onken JE, Bregman DB, Harrington RA, Morris D, Acs P, Akright B. A multicenter, randomized, activecontrolled study to investigate the efficacy and safety of intravenous ferric carboxymaltose in patients with iron deficiency anemia. Transfusion. 2014;54(2):30615 .

13. Mahey R, Kriplani A, Mogili KD, Bhatla N, Kachhawa G, Saxena R. Randomized controlled trial comparing ferric carboxymaltose and iron sucrose for treatment of iron deficiency anemia due to abnormal uterine bleeding. Int $\mathrm{J}$ Gynaecol Obstet. 2016;133(1):43-8.
14. Evstatiev R, Marteau P, Iqbal T, Khalif IL, Stein J, Bokemeyer B, et al. FERGIcor, a randomized controlled trial on ferric carboxymaltose for iron deficiency anemia in inflammatory bowel disease. Gastroenterology. 2011;141(3):846-53.

15. VanWyck DB, Mangione A, Morrison J, Hadley PE, Jehle JA, Goodnough LT. Large dose intravenous ferric carboxymaltose injection for iron deficiency anemia in heavy uterine bleeding: a randomized controlled trial. Transfusion. 2009;49(12):2719-28.

Cite this article as: Bharathi KR, Bhat $\mathrm{P}$. Effectiveness and safety of intravenous ferric carboxy maltose in anaemic women attending gynecological unit. Int J Reprod Contracept Obstet Gynecol 2022;11:405-9. 